\title{
RAPID NON-CONTACTING RESISTIVITY LOGGING OF CORE
}

P.D. Jackson ${ }^{1}$, M.A. Lovell ${ }^{2}$, J. Roberts ${ }^{3}$, P.D. Schultheiss ${ }^{3}$, D. Gunn ${ }^{1}$, R.C. Flint ${ }^{1,4}$, A. Wood ${ }^{5}$ and R. Holmes ${ }^{6}$

${ }^{1}$ British Geological Survey, Nottingham, NG12 5GG, UK

${ }^{2}$ Department of Geology, University of Leicester, LE1 7RH, UK

${ }^{3}$ Geotek Limited, 3 Faraday Close, Daventry, Northants. NN11 5RD United Kingdom

${ }^{4}$ Now at Dept. of Aeronautical \& Automotive Eng, Loughborough University, LE11 3TU

${ }^{5}$ Adrian Wood Associates, Danehill, Brookhill Rd, Copthorne, Crawley, RH10 3PS

${ }^{6}$ British Geological Survey, Edinburgh, EH9 3LA, UK

Corresponding Author: P D Jackson. Email pdj@bgs.ac.uk

Number of words of text, references, tables and figures; 2014 words

Abbreviated title $(<40$ characters)

RAPID NON-CONTACT RESISTIVITY CORE LOGGING 


\begin{abstract}
We demonstrate a non-contact approach to whole-core and split-core resistivity measurements, imaging a $15 \mathrm{~mm}$ thick, dipping, conductive-layer, producing a continuous log of the whole core and enabling a framework to enable representative plugs to be taken to be developed, for example. Applications include mapping subtle changes in grain fabric (e.g. grain shape) caused by variable sedimentation rates, for example, as well as the well-known dependencies on porosity and water saturation.
\end{abstract}

We demonstrate a non-contact approach to whole-core and split-core resistivity measurements. The capabilities demonstrated include:

- Imaging a $15 \mathrm{~mm}$ thick, dipping, conductive-layer

- Producing a continuous log of the whole core

- Enabling the development of a framework to enable representative plugs to be taken.

The method operates at relatively low frequencies (i.e. low induction numbers), needing highly sensitive coil pairs to provide resistivity measurements at the desired resolution. A four-coil arrangement, of two pairs of transmitter and receiver coils is used to stabilise the measurement. One 'coil pair' acts as a control, enabling the effects of local environmental variations, which can be considerable, to be removed from the measurement at source.

Comparing our non-contact approach and independent traditional 'galvanic' resistivity measurements indicates the non-contact measurements are directly proportional to the reciprocal of the sample resistivity (i.e. conductivity. The depth of investigation is discussed in terms of both theory and practical measurements and the response of the technique to a variety of synthetic 'structures' is presented.

We demonstrate the potential of the technique for rapid electrical imaging of core and present a whole core image of a dipping layer with azimuthal discrimination at a resolution of the order of $10 \mathrm{~mm}$. Consequently, the technique could be used to investigate different depths within the core, in agreement with theoretical predictions.

\title{
INTRODUCTION
}

Electrical resistivity is used as a primary method for reservoir characterisation, being related to porosity, porosity style and the nature of the fluids in the pore space (e.g. oil, water, or gas). Where sediment is fully saturated the resistivity changes will reflect changes in porosity and fabric, whereas changes in pore fluids may be dominant over these.

Traditionally, electrical resistivity measurements on core have used the galvanic approach where metal electrodes are attached to plugs of rock sub-sampled from full or half-round core. These galvanic resistivity measurements on core have benefits of potentially very fine resolving power and an independent depth of investigation (e.g. Jackson et al., 1995; Lovell et al., 1995). Their

disadvantages stem from the need for direct electrical contact between electrodes and core sample, and electrode polarization and contamination for example.

While cross-contamination between soft sediment cores is major issue in ocean research (e.g. in 
the Ocean Drilling Program), non-contact resistivity imaging at the well site was identified as needed in a study of research and development requirements in core analysis in the Petroleum Industry (HMSO/Department of Energy, 1991). 


\section{ELECTRICAL INDUCTION LOGGING OF CORE}

Following the successful introduction of galvanic electrical resistivity logging of boreholes in the 1930's induction logging became established in the 1950's (e.g. Doll, 1949), as it was capable of operation in oil-based muds. Non-contact EM conductivity measurement of the terrestrial land surface was introduced in the 1980's (McNeil, 1980), proving to be a rapid highly successful mapping technique. Moving a pair of coils at fixed separation over the surface of interest, we have adopted McNeil's approach to non-contact resistivity measurements on core samples. The method is summarized in Figures 1 and 2 where the cumulative response curves and the associated two different coil orientations can be seen. For a transmitter-receiver coil pair placed at the surface of a conducting 'earth', if the frequency is low enough, the traditional 'skin depth' (the tendency of alternating current to flow near the surface of a conductor), becomes large compared to the coil spacing, and the mutual induction of the secondary currents can be neglected (McNeil, 1979), in what is called the 'low induction number' criterion. Here the magnetic field, caused by the electric currents induced in the 'earth' is 90 degrees out of phase with the primary magnetic field exciting the transmitter, and is inversely proportional to the ground resistivity. Additionally, the current flowing in each layer within a horizontally layered earth would be independent of one another, while the contribution of each layer to the measurement is the inverse of the product of the layer's conductivity and the difference in cumulative response function between its upper and lower bounds (Figure 2).

\section{Design}

To improve resolution, pairs of small coils were developed for use at low induction numbers near the surface of core samples having the plane of the coils horizontal (vertical magnetic dipoles) as shown in Figure 2. Initially the sensors consisted of two $15 \mathrm{~mm}$ diameter coils placed $42 \mathrm{~mm}$ apart within transparent plastic holders (Figure 3). Subsequently, stability was increased using an additional pair of 'control' coils, situated $200 \mathrm{~mm}$ away responding to air alone (Figure 4). This simple device, unavailable for downhole or conventional terrestrial prospecting, has enabled both the sensitivity and range of the core measurements to be substantially improved. Figure 5 illustrates the relationship between the signals obtained at a transmitter and received coil-pair, showing the 90 degree phase shift and the greater noise on the far lower amplitude received signal.

\section{Calibration}

The performance of the system is verified in Figure 6 where the output measurements can be seen to be directly proportionately to fluid conductivity. Similarly this non-contact EM method is compared with both traditional galvanic measurements and published values for $\mathrm{NaCl}$ solutions of differing concentrations (Figure 7). These results confirm the performance of both the new non-contact method and conventional four-electrode galvanic measurements.

The performance of the non-contact resistivity approach for core measurements was investigated using a suite of synthetic samples of known geometry and properties. Each synthetic core was constructed inside a thick walled (10 mm) 90mm diameter (ID) perspex tube. Using the vertical dipole arrangement of coils (Figure 1), the measurement was relatively insensitive to the presence of the perspex wall. The response to simulated resistive layers within a uniform host- 
rock is shown in Figure 8, where the core is moved past the coil pair. This ability to map structure within a core is illustrated further in Figures 9 and 10 where a wedge and thin dipping layer are presented. Figure 9 shows an electrical image (made by mapping successive profiles along the core) for a resistive saturated sandstone surrounded by pore fluid. Note the sandstone core is cut with a sloping or dipping face to the left and a perpendicular face to the right. In Figure 10 a dipping conductive fracture within a saturated sandstone formation is simulated. The dipping layer case, being $15 \mathrm{~mm}$ thick, demonstrates the potential of the method to assess structure almost three times finer than the coil separation.

\section{Depth of Investigation}

Separate to this investigation of the ability of the method to image features along the core, we investigated the depth of penetration of the signal into the core by the non-contact measurement. This is illustrated in Figure 11 for a range of material resistivities. Here a $100 \mathrm{~mm}$ diameter plastic tube, sealed at one end, with the sensor coil pair situated beneath, was filled with varying depths of water for a range of fluid resistivities. The results show $50 \%$ of the contribution to the measurement comes from the closest $10 \mathrm{~mm}$ of material, demonstrating the technique will respond to structure within the core rather than averaging values over a given depth interval.

\section{Case examples}

Application of the non-contacting technique in scientific studies has recently been widely enabled through the integration of the non-contact methodology described here into the GEOTEK Multi Sensor Core Logger (MSCL). Two different environments are described here. Figure 12 shows resistivity formation factors acquired on core recovered off the Moroccan coast at about $31^{\circ} \mathrm{N} / 10^{\circ} \mathrm{W}$, water depth $1072 \mathrm{~m}$. When dealing with discontinuous core sections it is important to be aware of end effects; here in this example this results in a significant loss of data at each section limit due to a (small) air gap that was unavoidable between two sections measured successively.

A second application is shown in Figure 13 and Figure 14. Both samples are from the upper slope west of the Hebrides in areas of seabed with structured sidescan sonar backscatter indicating possible Holocene slope instability. Figure 13 shows core samples made predominantly of mud (57-72\% particles $<2$ microns) with unconfined shear strengths averaging approximately $4 \mathrm{kpa}$. A peak of magnetic susceptibility just below approximately $2.5 \mathrm{~m}$ is thought to originate from a thin layer of magnetite-rich rock granules. Figure 14 is mud (approximately 65\% particles $<2$ microns) with average unconfined shear strengths of approximately 10kpa in the upper part. This overlies a very irregular log response associated with a mud, which on the basis of the sidescan image is possibly a debris flow (approximate average $46 \%$ particles $<2$ microns). This lower interval appears to be slightly more cohesive with unconfined shear strengths averaging approximately $14 \mathrm{kpa}$.

\section{CONCLUSIONS}

We have described a new non-contact method for the rapid electrical logging of core. Experimental results on synthetic core and on saline solutions demonstrate the success of this approach, while results for core from offshore Morocco and offshore NW Europe show the 
applicability in ocean floor studies of saturated sediments. Wider application to hydrocarbon core has yet to be demonstrated but where conductive paths exist in the rock, it may yield useful additional core logs on which to base further sampling and special core analysis.

\section{ACKNOWLEDGEMENTS}

The development of the non-contact resistivity method for use on core samples arose from a recommendation form the Department of Energy study of Study of Research and Development Requirements in Core Analysis (HMSO, 1991). Research and development was co-funded by the DTI Offshore Supplies Office. Dr Thomas Frederichs of the University of Bremen is thanked for kindly providing the data for Figure 12. PDJ, DG, and RH acknowledge this paper is published with the permission of the Director, BGS.

\section{REFERENCES}

Carmichael R. S., 1982. Handbook of physical properties of rocks. Boca Raton, CRC Press Inc.1, 404 IS_BN 0-8493-0226-9 (v.1).

Doll, H.G. 1949. Introduction to induction logging and application to logging of wells drilled with oil base mud. Transactions of the American Iinstitute of Mining and Metallurgical Engineers, 186, 148-162.

HMSO, 1991. Study of research and development requirements in core analysis. Geoscience Report to the Department of Energy (OSO) October 1991. HMSO, 64 pp.

Jackson, P.D., Lovell, M.A., Harvey, P.K., Ball, J.K., Williams, C., Flint, R.C., Gunn, D.A., Ashu, A.P., and Meldrum, P.I., 1995; Electrical core imaging I: A new technology for high resolution investigation of petrophysical properties. Scientific Drilling, 5, 139-151.

Lovell, M.A., Harvey, P.K., Jackson, P.D., Flint, R.C., Gunn, D.A., Williamson, G., Ball, J.K., Ashu, A.P., and Williams, C., 1995. Electrical core imaging II: investigation of fabric and fluid flow characteristics. Scientific Drilling, 5, 153-164.

McNeil, J.D. 1979. Interpretive aids for use with electromagnetic (non-contacting) ground resistivity mapping. Forty-first European Association of Exploration Geophysicists meeting. Hamburg, June 1979.

McNeil, J.D., 1980. Electromagnetic terrain conductivity measurement at low induction numbers. Technical Note TN-6, GEONICS Limited, Ontario, Canada, 15p. 


\section{FIGURE CAPTIONS:}

Figure 1: Figure 1: Principle of the electromagnetic resistivity measurement at low induction number (skin depth >> coil spacing); Transmitter (Tx) and receiver (Rx) coils aligned to create vertical magnetic dipoles (left) and horizontal magnetic dipoles (right) (after McNeil, 1980).

Figure 2: Cumulative Responses from which theoretical measurements can be calculated for both horizontal dipole (lower curve, red) and vertical dipole (upper curve, blue) (after McNeil, 1980).

Figure 5: Relationship between Transmitter and Receiver signals.

Figure 3: Photograph of single pair of coils in test rig.

Figure 4: Photograph of twin-paired coils.

Figure 6: Calibration curves for both vertical and horizontal dipole configurations.

Figure 7: Comparison of galvanic and non-contact measurements of resistivity of salt solutions with published data (Carmichael, 1982).

Figure 8: Measurement response to an insulating "resistive” layer; top figure shows increased layer thickness.

Figure 9: Unwrapped image of test arrangement: resistive saturated sandstone bounded by conductive water.

Figure 10: Unwrapped image of a simulated conductive fracture bounded by saturated sandstone.

Figure 11: Response curves for varying water resistivities (see text for full description).

Figure 12: Non-contact resistivity formation factors: cored off Morocco in 1072m water depth.

Figure 13: Non-contact resistivity formation factors: cored off NW Europe.

Figure 14: Non-contact resistivity formation factors: cored off NW Europe. 


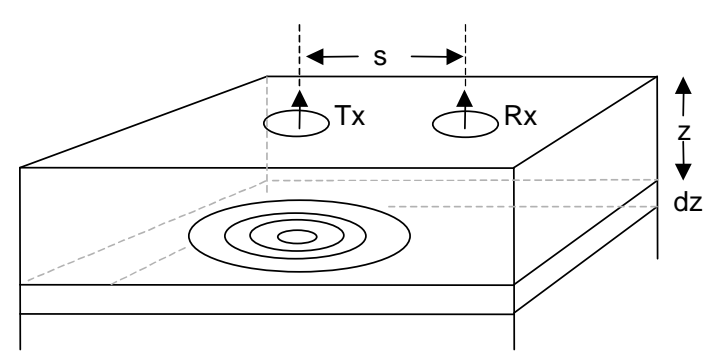

horizontal dipole (vertical coils)

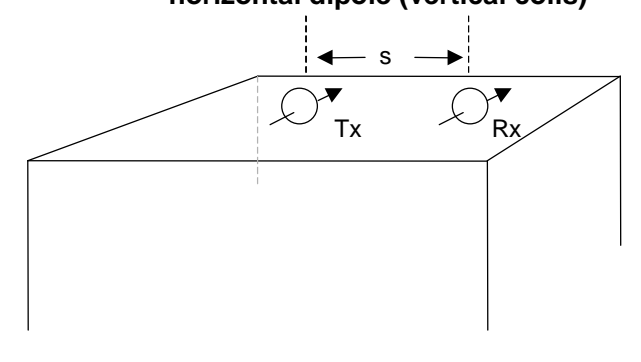

Figure 1: Principle of the electromagnetic resistivity measurement at low induction number (skin depth >> coil spacing); Transmitter (Tx) and receiver(Rx) coils aligned to create vertical magnetic dipoles (left) and horizontal magnetic dipoles (right) (after McNeil, 1980).

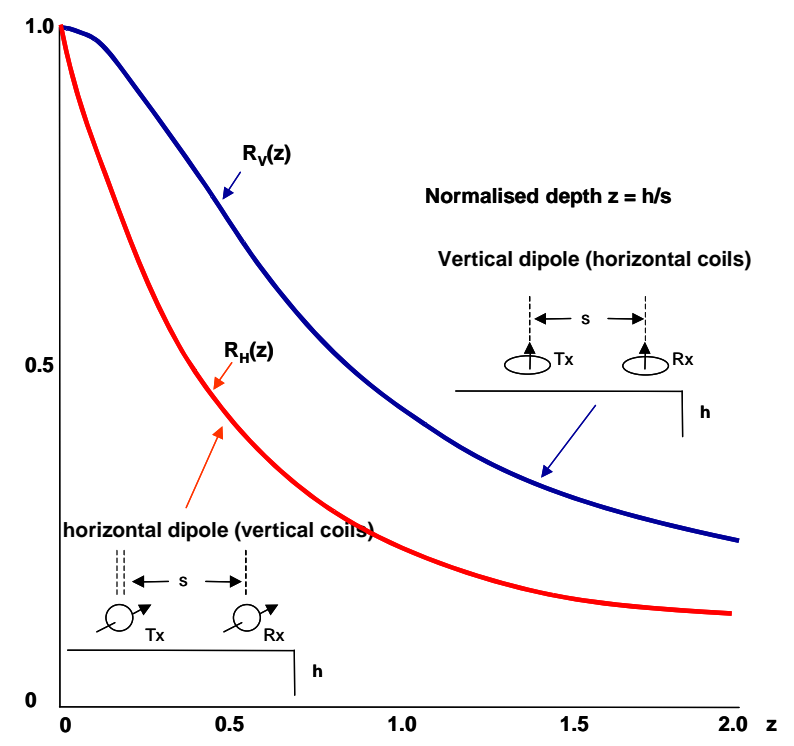

Figure 2: Cumulative Responses from which th eoretical measurements can be calculated for bothhorizontal dipole (lower curve, red) and vertical dipole (upper curve, blue) (after McNeil, 1980). 

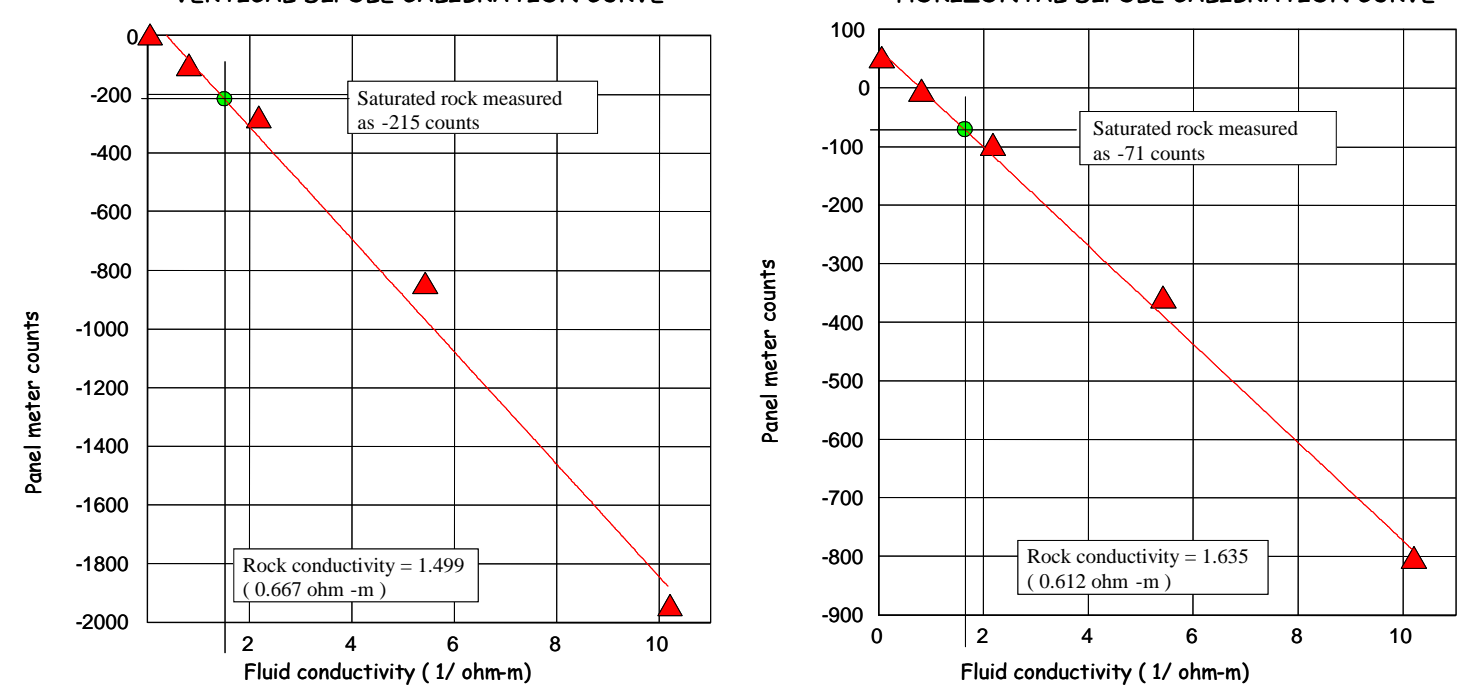

Figure 6: Calibration curves for both vertical and horizontal dipole configurations. 
Comparison of galvanic and non -contact induction

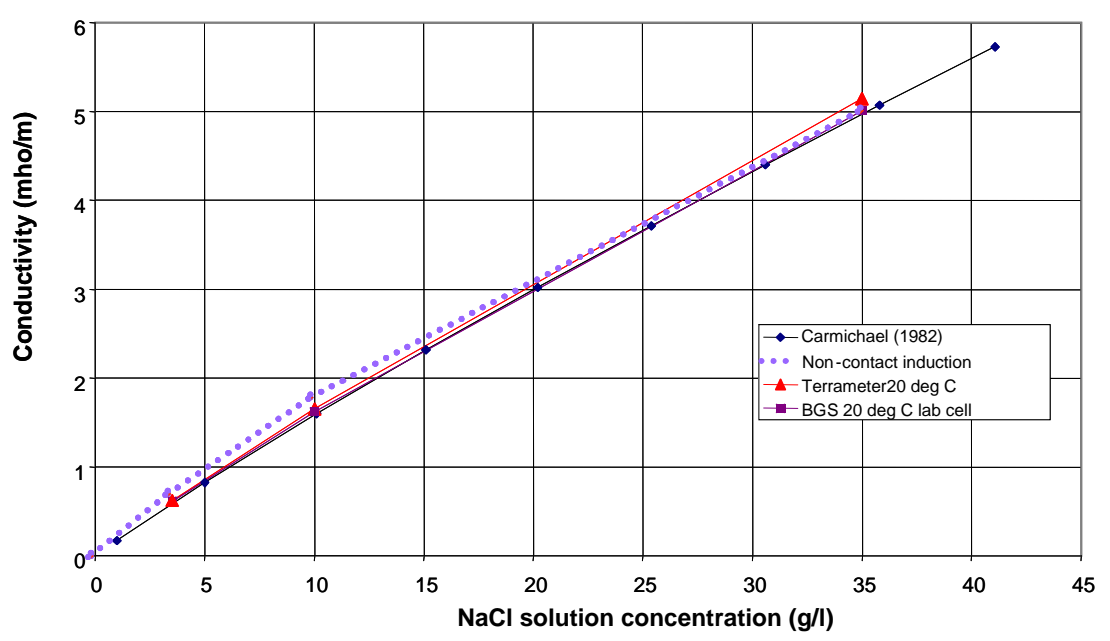

Figure 7: $\quad$ Comparison of galvanic and non contact measurements of resistivity of salt solutions. 

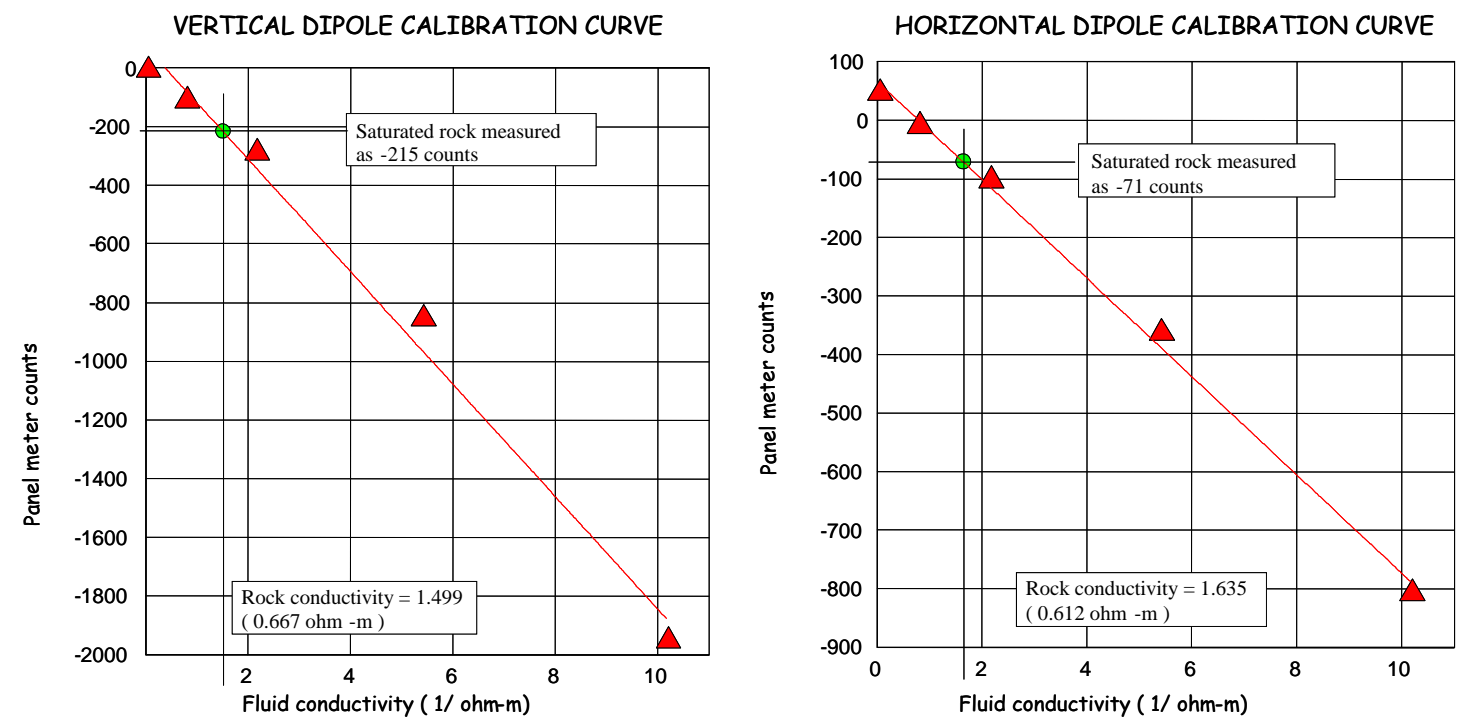

Figure 6: Calibration curves for both vertical and horizontal dipole configurations. 

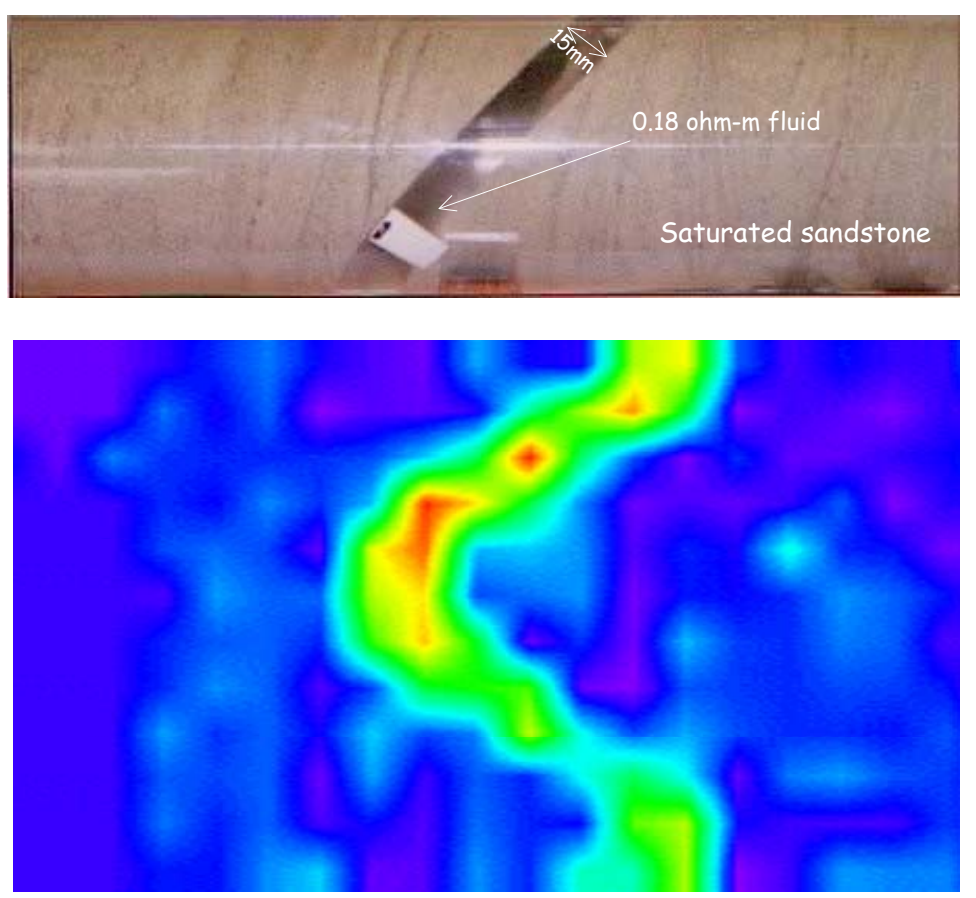

Figure 10: Unwrapped image of a simulated conductive fracture bounded by saturated 


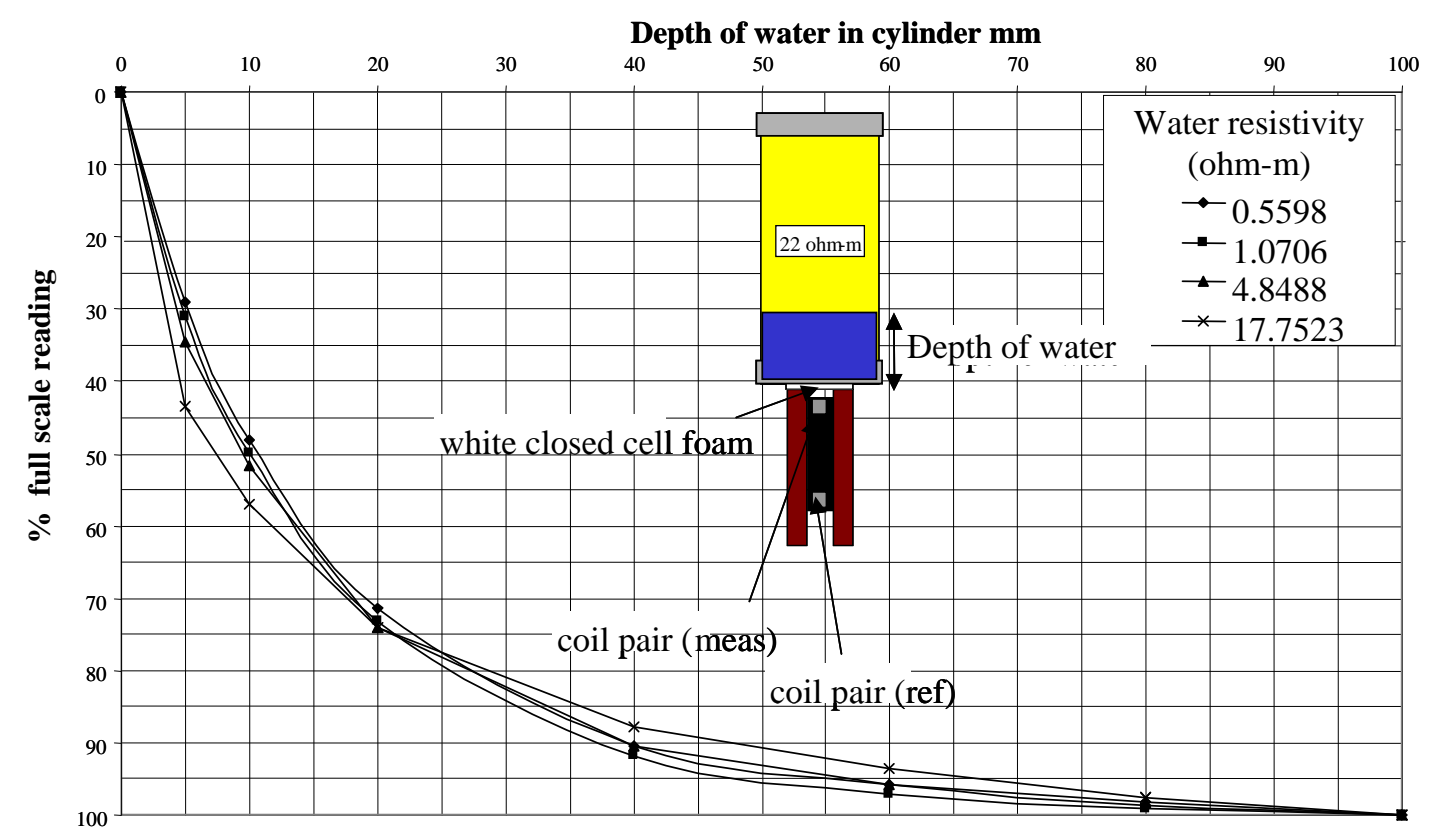

Figure 11: Response curves for varying water resistivities (see text for full description) 


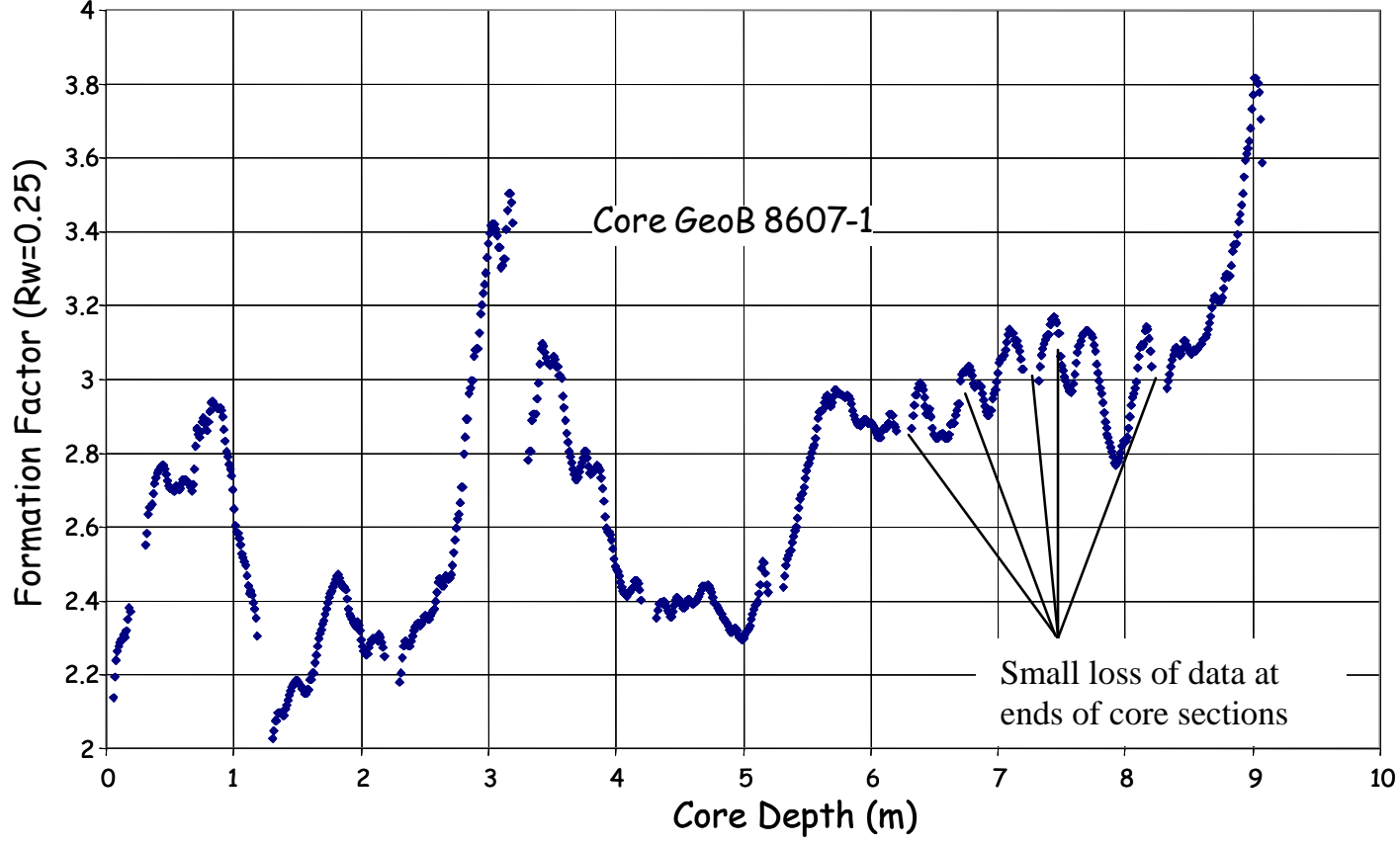

Figure 12: Non-contact resistivity formation factors: cored off Morocco in $1072 \mathrm{~m}$ water depth (kindly supplied by Dr Thomas Frederich at the University of Bremen). 


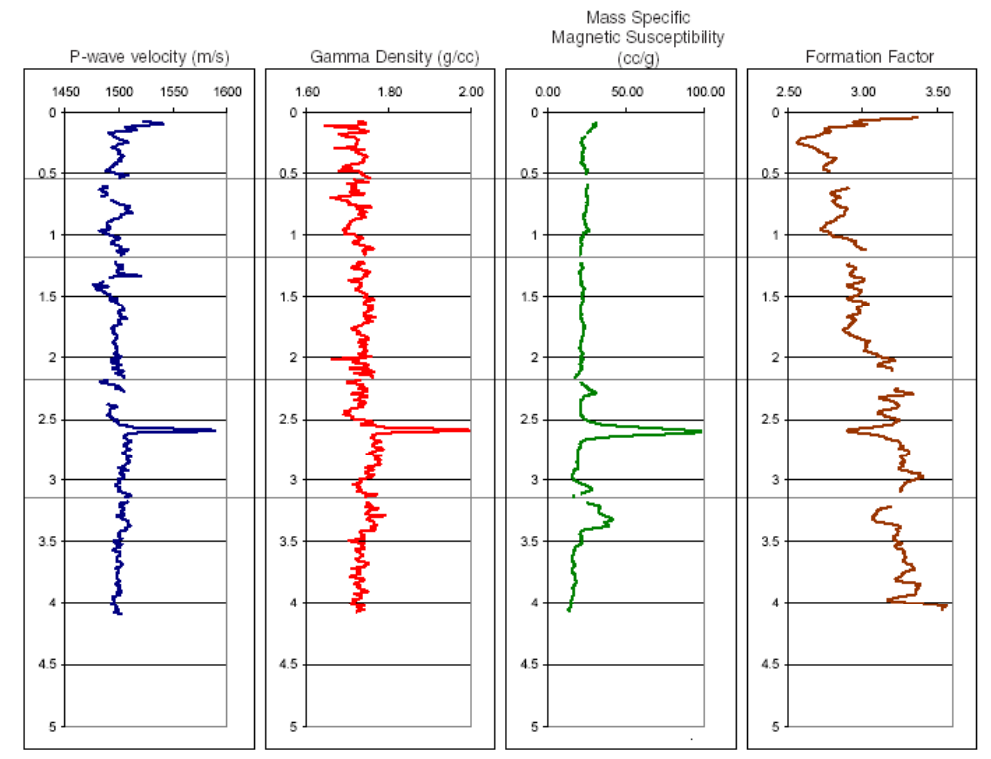

Figure 13: Non-contact resistivity formation factors: vibrocore samples from the upper slope west of the Hebrides. Magnetic susceptibility peak due to a thin layer of magnetite rich grains. 


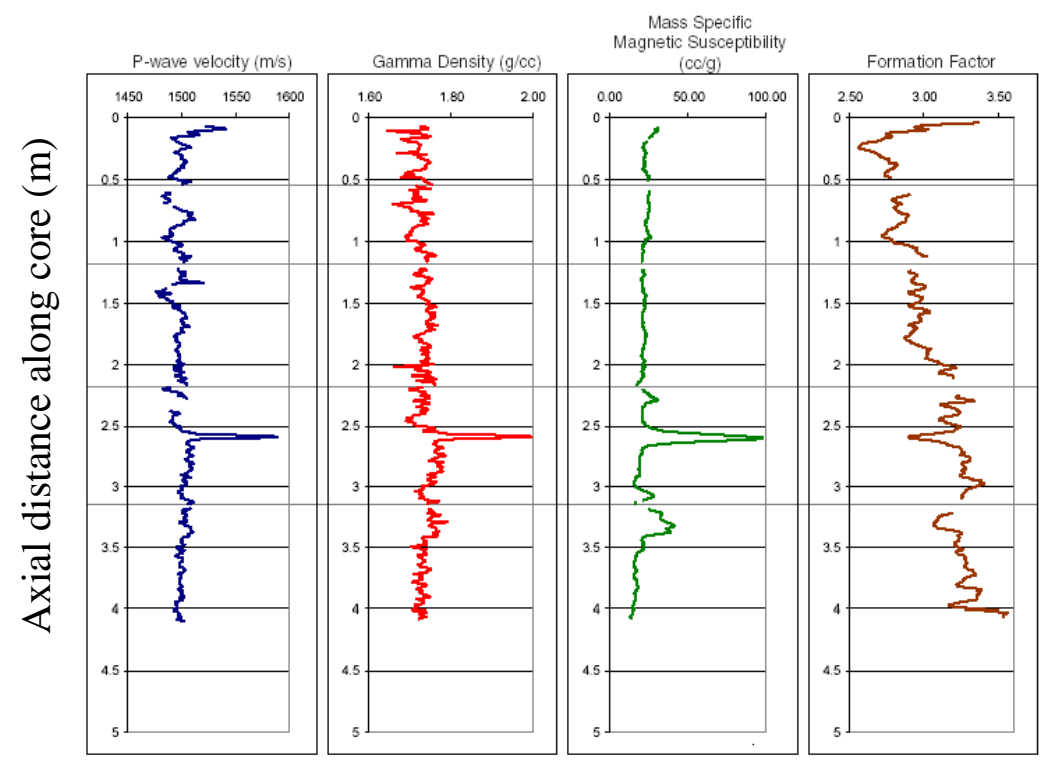




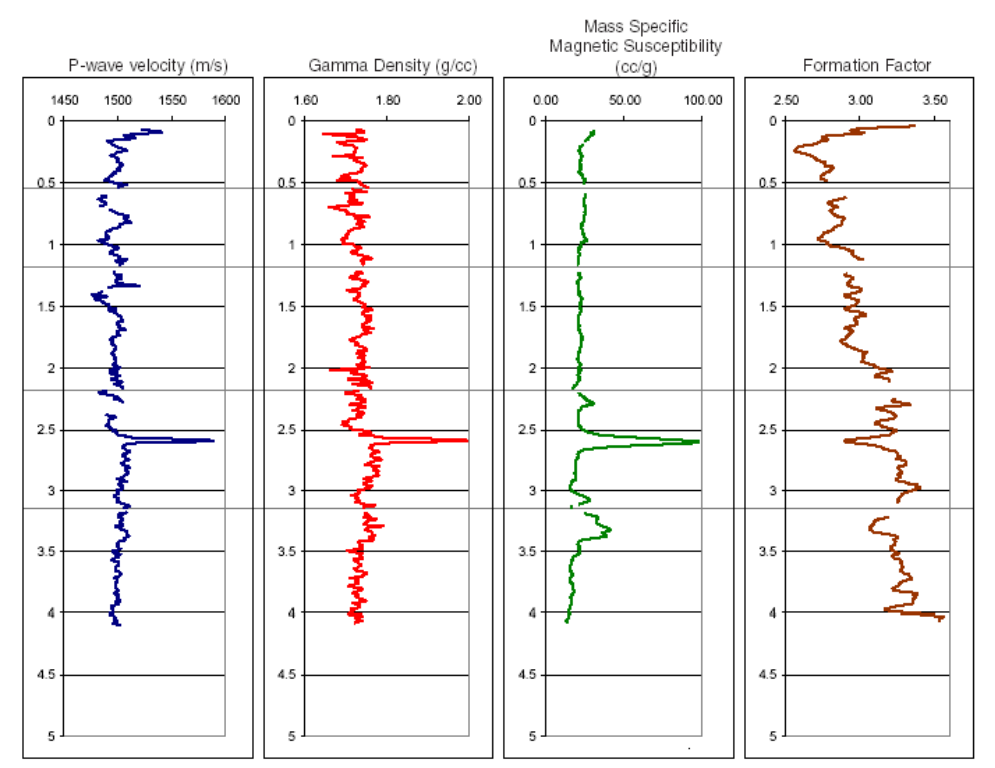

Enhanced metafile

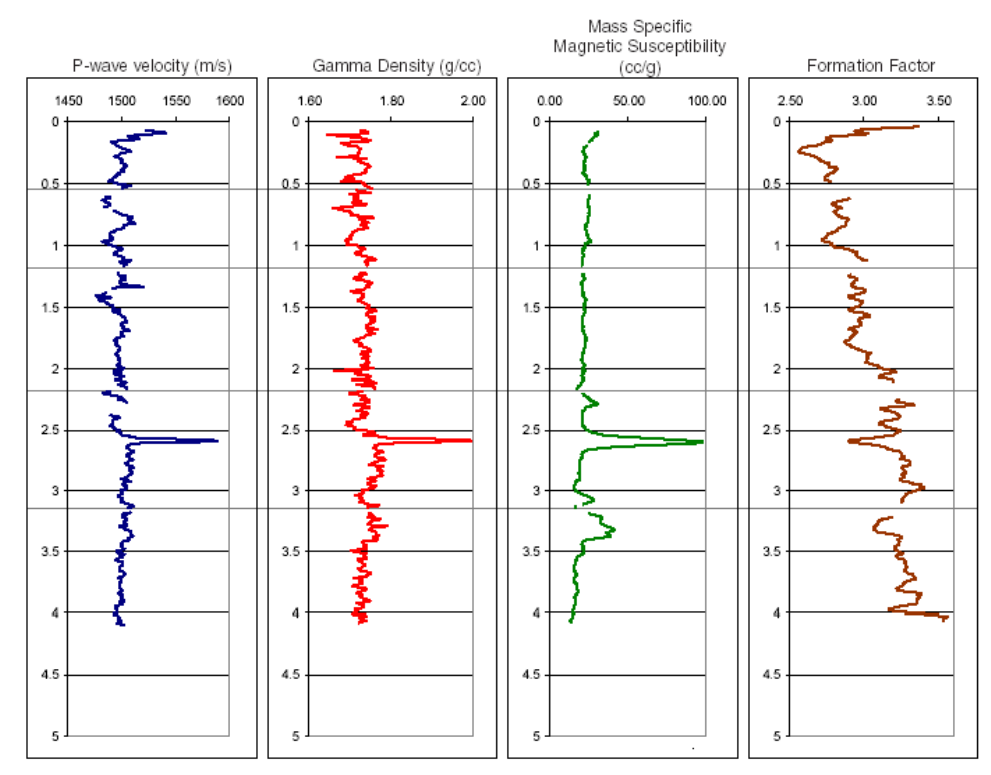

MS Office object

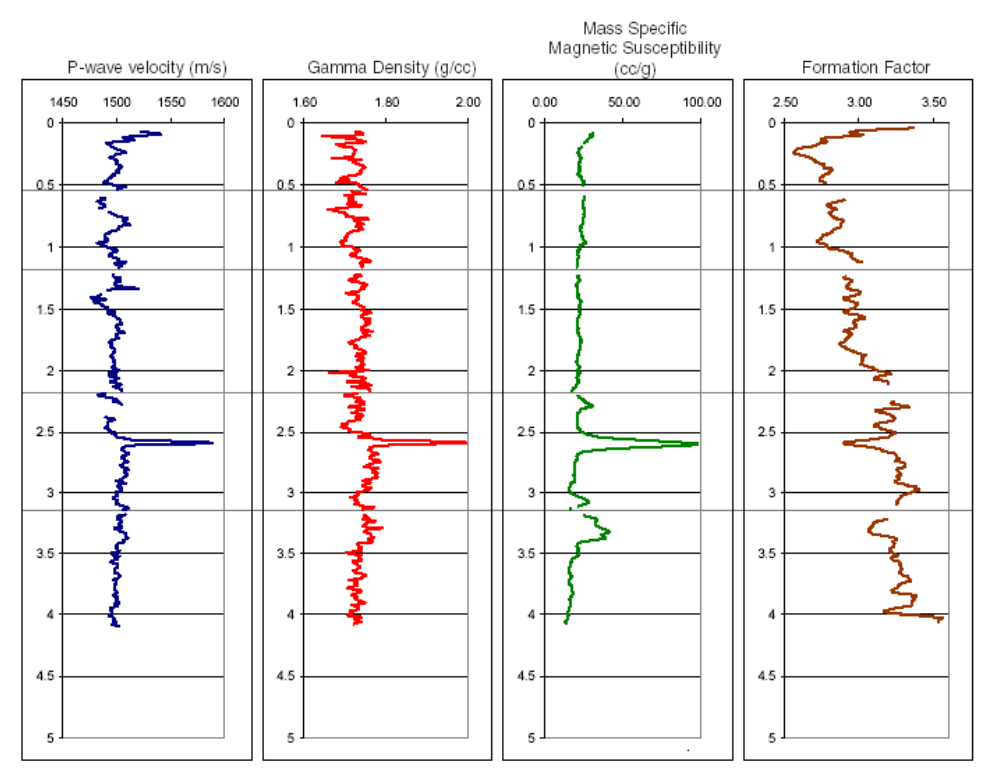

\section{Picture}
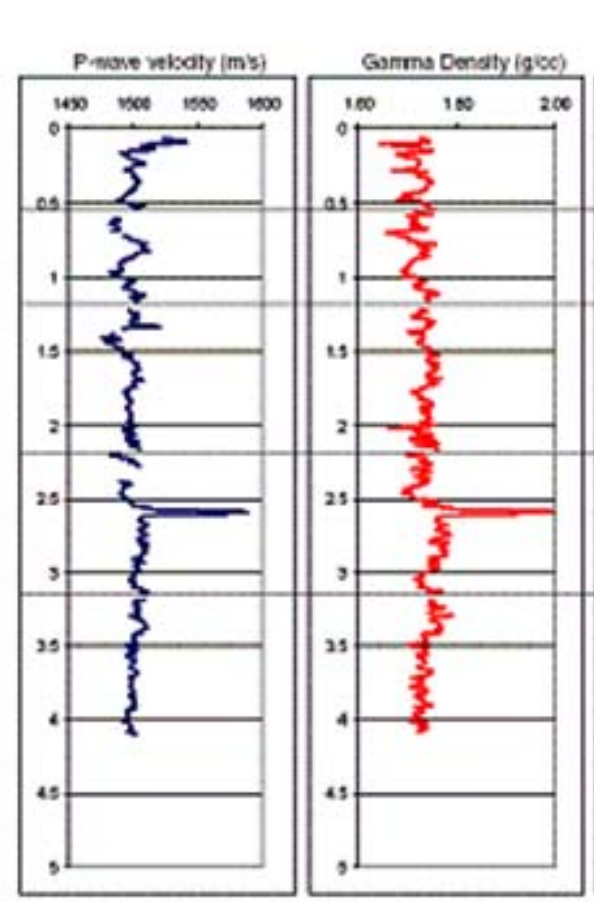

Mes spocite
Laghts \$asto ity

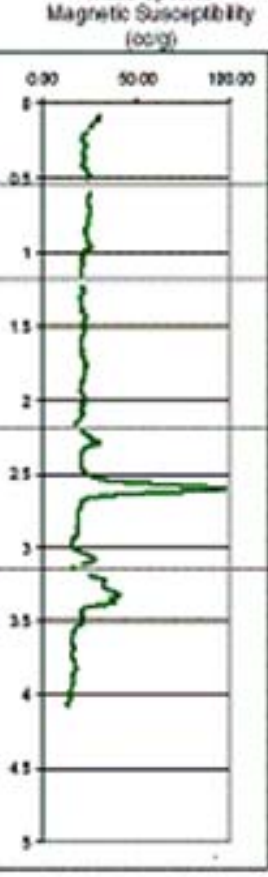

Formusson Focter

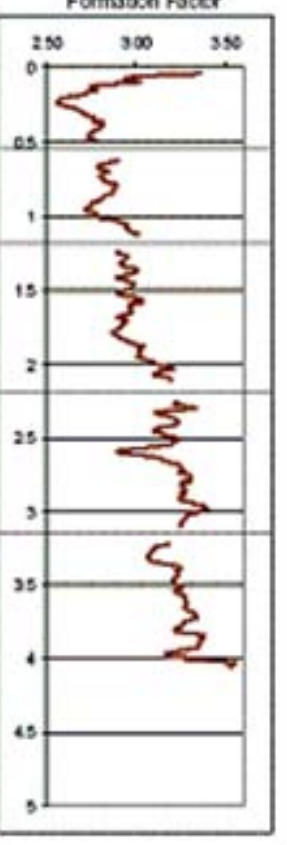

GIF 


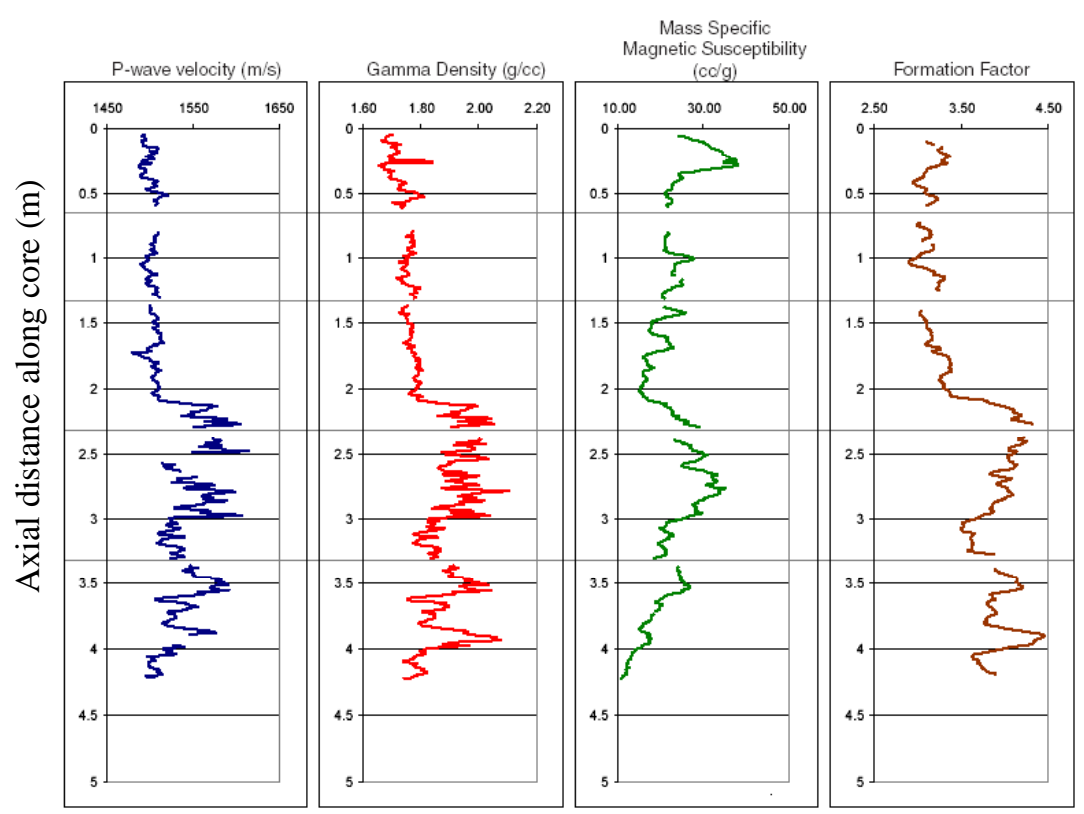

Figure 14: Noncontact resistivity formation factors: vibrocore samples from the upper slope west of the Hebrides indicating possible slope instability, very irregular log responses, perhaps a debris flow overlain by homogeneous muds. 


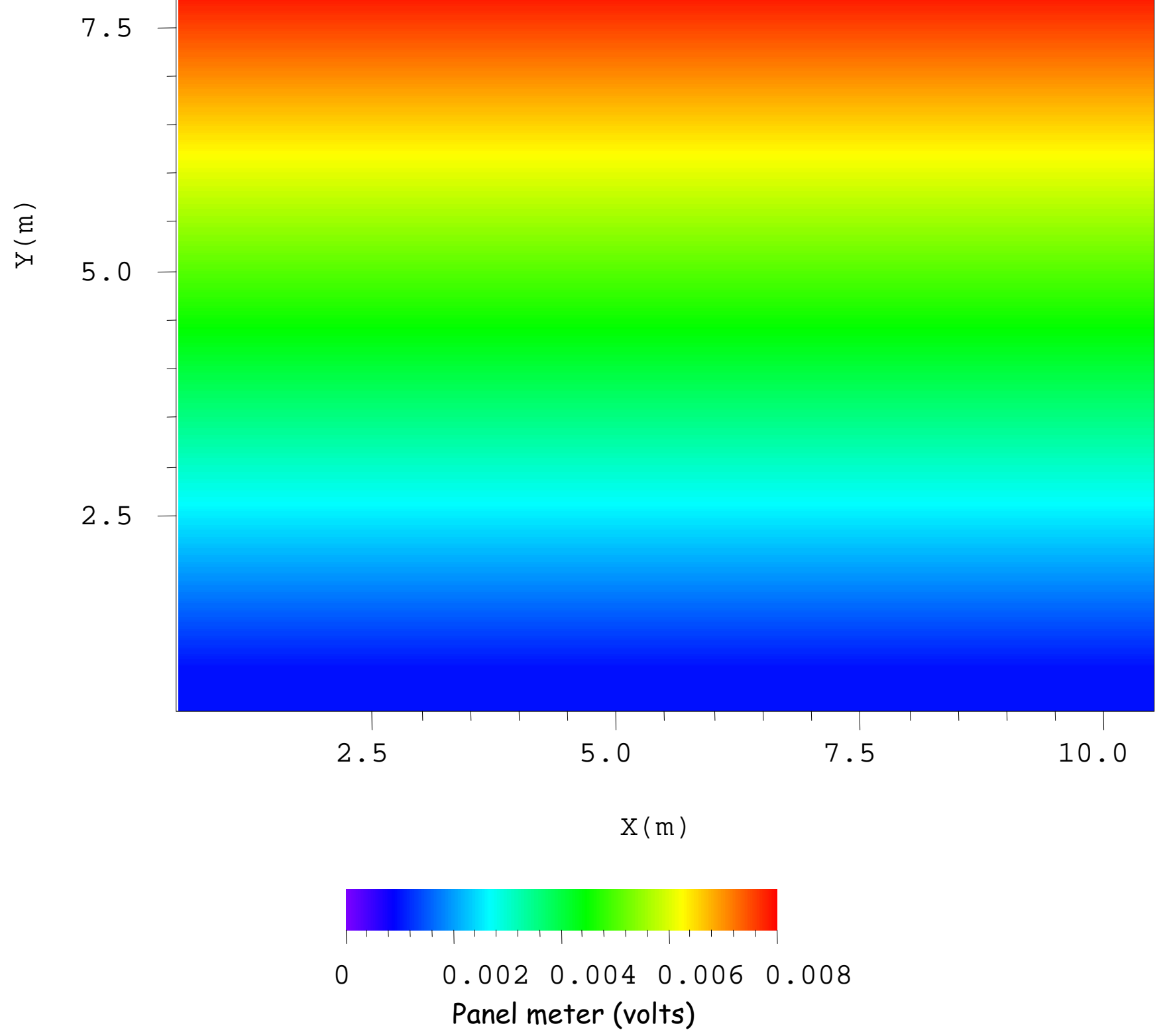

